\title{
Determinants of health after hospital discharge: rationale and design of the Vanderbilt Inpatient Cohort Study (VICS)
}

\author{
Abby G Meyers ${ }^{1}$, Amanda Salanitro ${ }^{2,3,4}$, Kenneth A Wallston ${ }^{5}$, Courtney Cawthon ${ }^{6}$, Eduard E Vasilevskis ${ }^{2,3,4}$, \\ Kathryn M Goggins ${ }^{6}$, Corinne M Davis ${ }^{6}$, Russell L Rothman ${ }^{4}$, Liana D Castel ${ }^{4}$, Katharine M Donato ${ }^{7}$, \\ John F Schnelle ${ }^{4,8}$, Susan P Bell ${ }^{9}$, Jonathan S Schildcrout ${ }^{10}$, Chandra Y Osborn ${ }^{4,11}$, Frank E Harrell ${ }^{10}$ \\ and Sunil Kripalani ${ }^{*}$
}

\begin{abstract}
Background: The period following hospital discharge is a vulnerable time for patients when errors and poorly coordinated care are common. Suboptimal care transitions for patients admitted with cardiovascular conditions can contribute to readmission and other adverse health outcomes. Little research has examined the role of health literacy and other social determinants of health in predicting post-discharge outcomes.

Methods: The Vanderbilt Inpatient Cohort Study (VICS), funded by the National Institutes of Health, is a prospective longitudinal study of 3,000 patients hospitalized with acute coronary syndromes or acute decompensated heart failure. Enrollment began in October 2011 and is planned through October 2015. During hospitalization, a set of validated demographic, cognitive, psychological, social, behavioral, and functional measures are administered, and health status and comorbidities are assessed. Patients are interviewed by phone during the first week after discharge to assess the quality of hospital discharge, communication, and initial medication management. At approximately 30 and 90 days post-discharge, interviewers collect additional data on medication adherence, social support, functional status, quality of life, and health care utilization. Mortality will be determined with up to 3.5 years follow-up. Statistical models will examine hypothesized relationships of health literacy and other social determinants on medication management, functional status, quality of life, utilization, and mortality. In this paper, we describe recruitment, eligibility, follow-up, data collection, and analysis plans for VICS, as well as characteristics of the accruing patient cohort.
\end{abstract}

Discussion: This research will enhance understanding of how health literacy and other patient factors affect the quality of care transitions and outcomes after hospitalization. Findings will help inform the design of interventions to improve care transitions and post-discharge outcomes.

Keywords: Hospitalization, Patient discharge, Patient readmission, Transitions of care, Health literacy, Social determinants

\footnotetext{
* Correspondence: sunil.kripalani@vanderbilt.edu

${ }^{4}$ Division of General Internal Medicine and Public Health, Department of Medicine, Vanderbilt University, 1215 21st Ave S, Suite 6000 Medical Center East, Nashville 37232, TN, USA

Full list of author information is available at the end of the article
} reproduction in any medium, provided the original work is properly cited. The Creative Commons Public Domain Dedication waiver (http://creativecommons.org/publicdomain/zero/1.0/) applies to the data made available in this article, unless otherwise stated. 


\section{Background}

\section{Hospital discharge and poor transitions in care}

Research has demonstrated that the period following hospital discharge is a vulnerable time for patients. As patients return home from the hospital, they must often manage new health care problems, changes in their medication regimen, and follow-up appointments, even as they continue to recover from an acute illness [1]. Medication errors, adverse drug events, and hospital readmission are major concerns [1]. For example, the 30day rehospitalization rate among Medicare beneficiaries is $19.6 \%$, with an estimated annual cost to Medicare of $\$ 17.4$ billion [2].

A better understanding is needed of which patients are at highest risk for adverse outcomes in this critical time period. Patients with cardiovascular conditions, such as acute coronary syndromes (ACS) or acute decompensated heart failure (ADHF), are a logical choice for study, as they are frequently required to manage a complex set of medications and other self-care activities after hospital discharge. In this context, suboptimal self-care, such as medication non-adherence, is common and is associated with recurrent cardiac events, re-hospitalization, and higher mortality [3]. Overall, the 30-day incidence of readmission following ACS is about 15\%; [4] the 1-year mortality in registries observing a broad spectrum of ACS patients is $2.3 \%$ to $8.6 \%$ [5,6]. For ADHF, the 30-day readmission rate is approximately $23 \%$, [7] and 1-year mortality after hospitalization is about $27 \%$ [8].

\section{Predictors of post-discharge outcomes}

Most studies that have examined predictors of postdischarge outcomes have looked only at variables that are readily available in administrative datasets [9]. Such work has shown, for example, that African Americans, older adults, and individuals in lower socioeconomic strata experience higher readmission rates [2]. Large ongoing observational studies are focusing on racial and gender disparities in post-hospitalization outcomes for patients with acute myocardial infarction [10,11]. Yet, relatively few studies have examined how complex and interrelated social factors may affect readmission and mortality after hospitalization [12,13].

Social determinants of health, which account for some health disparities, [14] include measures of sociodemographic, educational, cognitive, psychological, cultural, and behavioral variables [15]. Predictive models that include social determinants are better at forecasting readmission than models solely based on administrative data [9]. Health literacy is an important social determinant which affects a patient's ability to appropriately take medications, keep follow-up appointments, watch for signs of worsening illness, and know what to do if they occur [16]. Low health literacy is independently associated with hospital readmission, [17] as well as mortality [18]. Social support from friends or family is another important factor in the post-discharge period [12]. Such patient-level factors, as well as system-level factors like timeliness of post-discharge follow-up and quality of medication reconciliation, likely play a large role in post-discharge outcomes, but more in-depth measurement and analysis of such factors is needed to determine their relative contributions and interrelationships [12].

In addition to informing risk prediction, a better understanding of determinants of health after hospitalization will inform intervention delivery. Many studies have examined the efficacy of interventions to improve care transitions and reduce hospital readmission, some tailored to a patient's level of health literacy and social circumstances [19]. Most interventions are deployed across broad patient populations, though some studies identify high-risk patients for intervention, on the basis of medical or psychiatric conditions, functional status, previous admissions, age, or other factors. However, what characteristics define a high-risk state varies across studies. Improved ability to identify high-risk patients through more robust assessment of their social determinants would facilitate more targeted, efficient, and cost-effective delivery of transitional care interventions [20].

We delineate a model to guide further study of social determinants of health after hospital discharge (Figure 1), which is based in part on a prior model relating health literacy and self-care to health outcomes [21]. The figure displays (from left to right) demographic attributes such as age, race, ethnicity, and socioeconomic standing that influence health status, social support, and health literacy. In turn, these three aspects affect how patients interact with the healthcare system, the healthcare providers, and the ability to manage their disease(s). Ultimately, all factors impact health outcomes of interest, including functional status, health-related quality of life, unplanned healthcare utilization, and mortality. (For clarity, not all posited relationships are marked with arrows. For example, socioeconomic status may directly affect health care utilization).

\section{Aims of the Vanderbilt Inpatient Cohort Study (VICS)}

The Vanderbilt Inpatient Cohort Study (VICS) is a 5year prospective longitudinal cohort study funded by the National Heart, Lung, and Blood Institute of the $\mathrm{Na}$ tional Institutes of Health. Its goal is to examine how health literacy and other social determinants affect the quality of care transitions from hospital to home, as well as subsequent health outcomes including medication use, functional status, health-related quality of life, unplanned health care utilization, and mortality. Moreover, we seek to determine mediators and moderators of these relationships. Some social determinants could be amenable to 


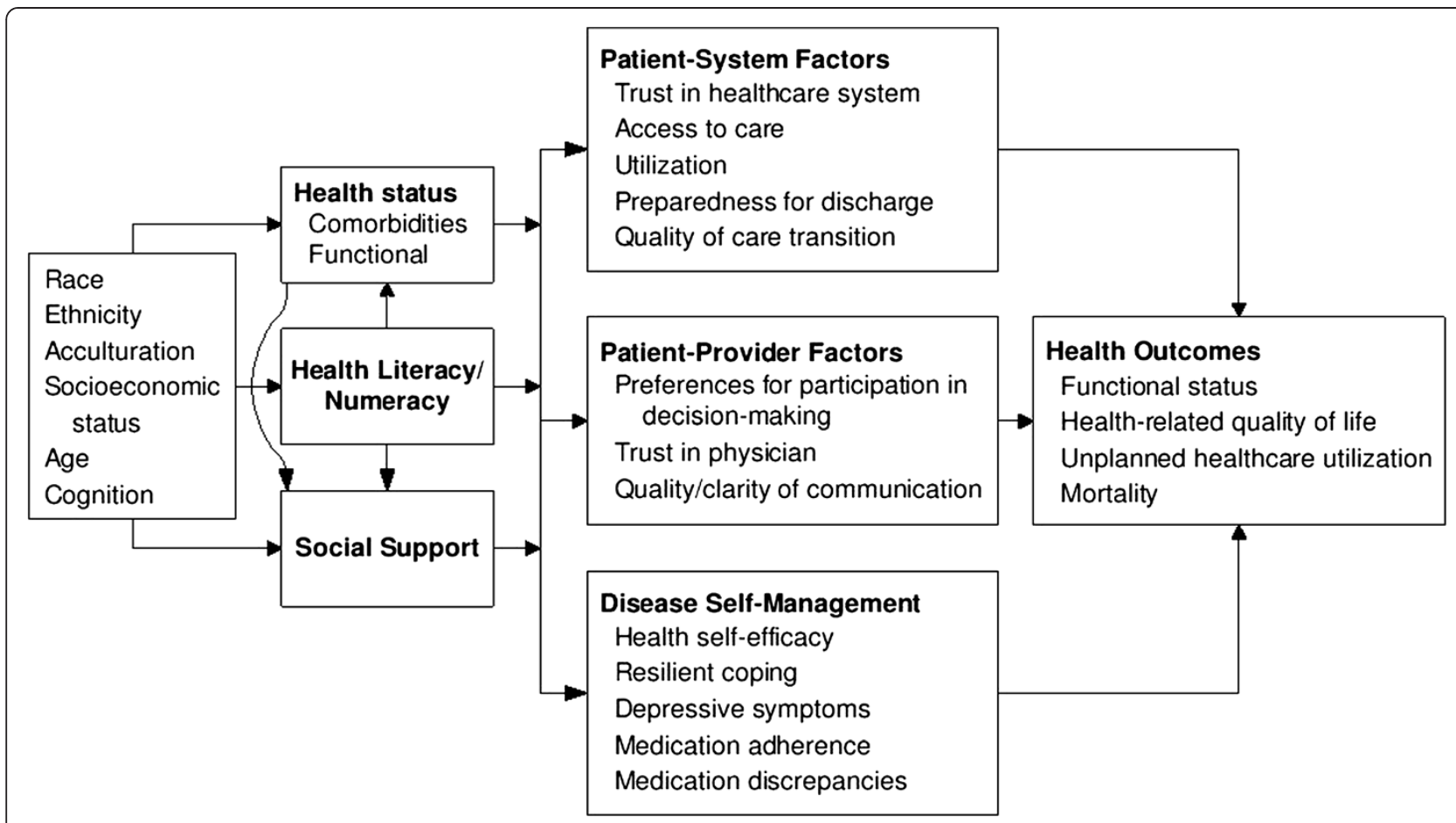

Figure 1 Framework relating patient characteristics to health outcomes.

subsequent interventions that modify or accommodate them to improve health outcomes. Just as personalized medicine can customize health decisions based on a patient's genetic code, healthcare and quality improvement initiatives can also be personalized based on demographic and social factors. Understanding these factors can help us not only tailor care more specifically to fit individuals' needs and preferences, but also help improve healthcare quality and outcomes.

\section{Methods}

\section{Study sample}

Patient enrollment for VICS began in October 2011, and is scheduled to end in October 2015, with the goal of enrolling 3,000 patients. Adults admitted to Vanderbilt University Hospital or an affiliated community hospital, Williamson Medical Center, are eligible. Monday through Saturday, staff screen the hospital's electronic medical records to identify patients who presented to the hospital with symptoms suggestive of ADHF and/or intermediate to high likelihood of ACS. A study investigator (hospitalist or cardiologist) confirms the diagnosis by chart review. Research assistants (RAs) then assess the presence of the following exclusion criteria: age $<18$ years, inability to communicate in English, blindness, hearing impairment, lack of a working telephone, conditions that would interfere with the validity of the interview (e.g., significant dementia, active psychosis or mania), being near the end of life (hospice or home hospice), lack of cooperation, police custody, enrollment in a conflicting study, or prior enrollment in VICS. Patients who are delirious or too ill to participate early in their hospitalization, but who would be eligible otherwise, are re-assessed for up to 7 days for potential eligibility. Because many of the instruments are designed for patient self-assessment, we do not enroll surrogates to respond on the patient's behalf. Approaching members of racial/ethnic minority groups and women is prioritized to promote their representation in the study sample.

\section{Study procedures}

The VICS protocol was reviewed and approved by the Vanderbilt University Institutional Review Board. After obtaining written informed consent, RAs verbally administer the 45-minute baseline interview at the bedside. RAs have received thorough training in effective health communication, including best practices in informed consent, recruitment, and interviewing techniques. Patients are contacted by telephone for follow-up interviews at 2-3 days (range 1-7), 30 days (range 25-35), and 90 days (range 8595) after discharge. These calls require approximately 15 , 15 , and 7 minutes, respectively. Additional data (e.g., measures of disease severity, comorbidities, laboratory values, verification of health care utilization) are obtained from the electronic health record and by chart abstraction. Figure 2 provides an overview of the study flow. 


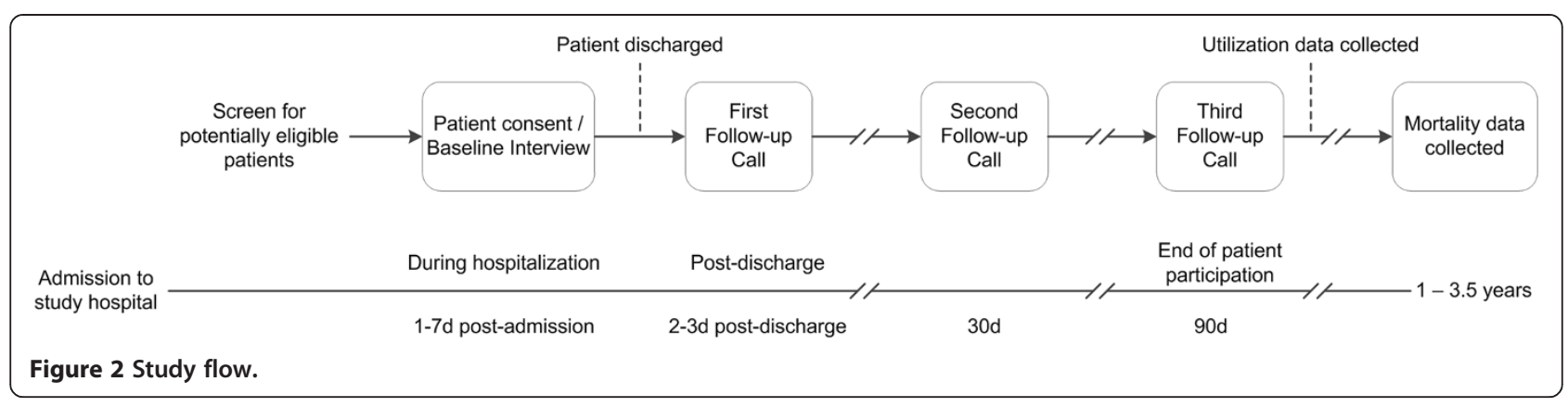

\section{Interview measures and data collection}

Study data are collected and managed using the Research Electronic Data Capture (REDCap) platform [22]. REDCap is a secure, web-based application designed to support research data entry, validation, and management.

The domains assessed and their specific measures are presented and briefly described in Table 1 . Data collection and analyses are grounded in the study's conceptual framework (Figure 1).

\section{Demographics}

The baseline interview includes demographic items, contact information, employment status, educational attainment, annual household income, and marital status. Acculturation is measured using the Generic Brief Acculturation Scale (GBAS) in participants whose primary language is not English [23]. This 3-item instrument asks participants about their use of English (versus another language) to read, speak, think, and converse with friends. Cognition is assessed using the Short Portable Mental Status Questionnaire (SPMSQ), [24] a 10-item instrument that adjusts for educational level.

\section{Disease severity and health status}

Measures of disease severity are abstracted from the patient's chart, including: transfer from another hospital, need for intensive care, electrocardiogram (EKG) changes, ejection fraction, stent placement, bypass surgery, and the presence of shock, life-threatening arrhythmia, and cardiac arrest. Additionally, the prognostic cardiovascular risk of patients' ACS is recorded as the clinicianreported Thrombolysis in Myocardial Infarction (TIMI) risk score [25].

Health status is represented in part by the Elixhauser index, which summarizes the presence or absence of 30 medical comorbidities [26]. Patients also report their subjective global health status at baseline through selected items pertaining to health and well-being from the NIH Patient Reported Outcomes Measurement Information System (PROMIS) [27].

Among patients aged 65 or older, vulnerability and functional status are assessed using the Vulnerable Elders Survey (VES-13), [28] a validated instrument that assesses participants' activities and instrumental activities of daily living (ADLs and IADLs). Frailty is assessed using the exhaustion items from the Center for Epidemiologic Studies Depression Scale (CES-D), [29] self-report of unintentional weight loss prior to admission, and grip strength.

\section{Health literacy and numeracy}

Health literacy is assessed using the short form of the Test of Functional Health Literacy in Adults (s-TOFHLA), [30] a 7-minute timed test that categorizes health literacy as inadequate, marginal, or adequate. Subjective health literacy is also assessed using the 3-item Brief Health Literacy Screen (BHLS) [31].

Numeracy, which is the ability to access, understand, and apply numerical data, is measured using a shortened 3-item version of the Subjective Numeracy Scale (SNS) [32]. This self-reported measure assesses participants' comfort with numerical data through items about math skills and preferences for numerical information.

\section{Social support}

Social support of friends, family, and neighborhood prior to hospitalization is assessed using measures that characterize emotional and instrumental support, as well as companionship. Items from the Health and Retirement Survey (HRS) ask participants to estimate the number of friends and family members with which they have a close relationship [33]. Additionally, items from the Midlife Development in the United States (MIDUS) survey measure frequency of contact and level of support from friends, family, and neighbors [34]. The ENRICHD Social Support Inventory (ESSI) complements these by asking about any other sources of emotional support [35].

Social support during the post-discharge period is assessed during the first follow-up call, as hospitalization may change the quality and quantity of social support received. The Instrumental Support after Discharge (ISD) survey asks about specific forms of support that participants receive with common care transition tasks, such as obtaining prescriptions, understanding the medication regimen, or transportation. Items from the MIDUS and ESSI are re-administered at the 30-day interview. 
Table 1 Data collection

\begin{tabular}{|c|c|c|c|c|c|c|}
\hline Domain & Scale & Description & Baseline & 2-3 Days & 30 Days & 90 Days \\
\hline Demographics & From BRFSS [49] & Race, ethnicity, place of birth & $x$ & & & \\
\hline Acculturation & GBAS [23] & Language-based measure of acculturation & $x$ & & & \\
\hline Income/socioeconomic status & & $\begin{array}{l}\text { Annual household income, difficulty paying bills, } \\
\text { employment and education status }\end{array}$ & $x$ & & & \\
\hline Social support & $\begin{array}{l}\text { HRS, MIDUS, ESSI } \\
{[33-35]}\end{array}$ & $\begin{array}{l}\text { Marital status, number in household, number of } \\
\text { close family/friends and frequency of contact, } \\
\text { perceived social support }\end{array}$ & $x$ & & $x$ & \\
\hline Health literacy & s-TOFHLA [30] & $\begin{array}{l}\text { Ability to perform basic reading tasks typical of } \\
\text { those encountered in the health care setting }\end{array}$ & $x$ & & & \\
\hline Subjective health literacy & BHLS [31] & Confidence with written medical information & $x$ & & & \\
\hline Subjective numeracy & SNS [32] & Preferences for numerical information & $x$ & & & \\
\hline Cognition & SPMSQ [24] & Level of cognitive impairment & $x$ & & & \\
\hline Access to care & & Presence of a regular health care provider & $x$ & & & \\
\hline Prior health care utilization & & $\begin{array}{l}\text { Number of hospital admissions, Emergency } \\
\text { Department visits, and outpatient clinic visits } \\
\text { during the last year }\end{array}$ & $x$ & & & \\
\hline Medication adherence & ARMS [52] & Adherence to medication regimen & $x$ & & $x$ & \\
\hline Quality of life & $\begin{array}{l}\text { PROMIS* Global } \\
\text { health status [27] }\end{array}$ & $\begin{array}{l}\text { Physical functioning, pain, fatigue, emotional } \\
\text { distress, and social health }\end{array}$ & $x$ & & $x$ & $x$ \\
\hline Depression & PHQ-8 [47] & Presence and severity of depressive symptoms & $x$ & & $x$ & \\
\hline $\begin{array}{l}\text { Vulnerable Elders Survey } \\
\text { ( } \geq 65 \text { yrs only) }\end{array}$ & VES-13 [28] & Health status, functional ability, and physical fitness & $x$ & & $x$ & $x$ \\
\hline Exhaustion ( $\geq 65$ yrs only) & CES-D [29] & $\begin{array}{l}\text { Perception that everything is an effort, trouble } \\
\text { getting going }\end{array}$ & $x$ & & & \\
\hline Health self-efficacy & PHCS [45] & $\begin{array}{l}\text { Confidence in engaging in appropriate } \\
\text { health-related behaviors }\end{array}$ & $x$ & & & \\
\hline $\begin{array}{l}\text { Problem-solving and } \\
\text { Decision-making }\end{array}$ & PSDM [41] & $\begin{array}{l}\text { Preferences in health-related problem-solving, } \\
\text { decision-making }\end{array}$ & $x$ & & & \\
\hline Diet & STC [50] & Healthy eating habits & $x$ & & & \\
\hline Physical activity & $\begin{array}{l}\text { Exercise vital } \\
\text { sign [51] }\end{array}$ & Exercise frequency and duration & $x$ & & & \\
\hline Smoking history & From BRFSS [49] & Past and current smoking status & $x$ & & & \\
\hline Alcohol consumption & From BRFSS [49] & Current alcohol intake & $x$ & & & \\
\hline Trust in health care system & RHCSDS [36] & General beliefs about the health care system & $x$ & & & \\
\hline Resilient coping & BRCS [46] & $\begin{array}{l}\text { Tendency to cope with stress in a highly adaptive } \\
\text { manner }\end{array}$ & $x$ & & & \\
\hline Religion/spirituality & & $\begin{array}{l}\text { Religious preference and denomination, intrinsic } \\
\text { religious/spiritual orientation, and frequency of } \\
\text { engaging in public or private religious/spiritual } \\
\text { activities }\end{array}$ & $x$ & & & \\
\hline Electronic health literacy & eHEALS [37] & Experience using the Internet for health information & $x$ & & & \\
\hline Use of portals & & Use of Vanderbilt online patient portal & $x$ & & & \\
\hline Trust in hospital providers & WFPTS [42] & $\begin{array}{l}\text { Interpersonal relationship between patient and } \\
\text { providers }\end{array}$ & & $x$ & & \\
\hline $\begin{array}{l}\text { Quality of communication } \\
\text { in hospital }\end{array}$ & IPC $[43,44]$ & $\begin{array}{l}\text { Quality and clarity of communication between } \\
\text { patient and provider }\end{array}$ & & $x$ & & \\
\hline Preparedness for discharge & B-PREPARED [39] & $\begin{array}{l}\text { Perceptions of the discharge planning process and } \\
\text { their level of preparation }\end{array}$ & & $x$ & & \\
\hline Quality of the care transition & CTM-3 [40] & Care transition experiences & & $x$ & & \\
\hline Instrumental support & ISD & Support received with common care transition tasks & & $x$ & $x$ & \\
\hline
\end{tabular}


Table 1 Data collection (Continued)

\begin{tabular}{|c|c|c|c|c|c|}
\hline Stress post-discharge & & $\begin{array}{l}\text { Stress post-discharge, contribution of financial, } \\
\text { social/family, work, health, or other factors to stress }\end{array}$ & $x$ & & \\
\hline Medication discrepancies [53] & & $\begin{array}{l}\text { Unintentional differences between hospital } \\
\text { discharge regimen and what the patient thinks } \\
\text { s/he should be taking }\end{array}$ & $x$ & & \\
\hline Medication understanding [54 & & $\begin{array}{l}\text { Understanding of drug indications and instructions } \\
\text { for use }\end{array}$ & $x$ & & \\
\hline $\begin{array}{l}\text { Outcomes: ER visits and } \\
\text { hospitalization }\end{array}$ & & Unplanned healthcare utilization after discharge & & $x$ & $x$ \\
\hline Health-related quality of life & EQ-5D [55] & $\begin{array}{l}\text { Mobility, self-care, usual activities, pain, and } \\
\text { depression }\end{array}$ & & $x$ & $x$ \\
\hline Cardiac rehabilitation & & $\begin{array}{l}\text { Participation in cardiac rehab, and frequency } \\
\text { (if participating) }\end{array}$ & & $x$ & $x$ \\
\hline Outcomes: mortality & & $\begin{array}{l}\text { Through } 1 \text { year after last patient is enrolled and } \\
\text { discharged }\end{array}$ & & & \\
\hline \multicolumn{6}{|l|}{ Medical record abstraction } \\
\hline Demographics & & Age, gender & & & \\
\hline Diagnosis & & ACS, ADHF, or both & & & \\
\hline Severity of illness & & Including TIMI score, [25] ejection fraction & & & \\
\hline Comorbidities & & Including Elixhauser [26] & & & \\
\hline Insurance type & & $\begin{array}{l}\text { Including private, Medicare, Medicaid, none, } \\
\text { or other }\end{array}$ & & & \\
\hline Utilization & & $\begin{array}{l}\text { Post-discharge ER visits and readmissions } \\
\text { (to supplement patient-report) }\end{array}$ & & & \\
\hline
\end{tabular}

${ }^{*}$ A shortened 5-item version of the PROMIS measure is administered at baseline; the full 10-item version is administered at 30 and 90 days.

\section{Patient-system factors}

Prior health care utilization is a strong predictor of future utilization; [9] therefore, participants are asked at baseline to report the number of hospital admissions, emergency department visits, and outpatient clinic visits during the last year prior to the index admission.

Trust in the healthcare system is measured at baseline using the Revised Health Care System Distrust Scale (RHCSDS), [36] which assesses patient perceptions of honesty, confidentiality, competence, and fidelity.

Access to care is determined by the self-reported presence of a regular health care provider at baseline. The participant's access to and use of the Internet is assessed at baseline using items from the eHealth Literacy Scale (eHEALS) [37]. From electronic health records, the participant's health insurance, administrative details about the index hospitalization and prior utilization, and whether the participant left the hospital against medical advice (AMA) are obtained. Leaving AMA has been shown to predict readmission, as well as higher mortality [38].

The quality of discharge planning is assessed during the post-discharge telephone call using the B-PREPARED instrument, [39] which measures participants' perceptions of the discharge planning process and their level of preparation for performing self-care. Additionally, the quality of the care transition from hospital to home is measured using the Care Transitions Measure-3 (CTM-3) [40]. Both the B-PREPARED and CTM-3 measures have been shown to predict hospital readmission.

\section{Patient-provider factors}

Patients' preferences for participation in decision-making are determined using two vignettes from the ProblemSolving Decision-Making Scale (PSDM), [41] which elicits the extent to which participants prefer to share the decision-making process with their physician.

Trust in hospital providers is assessed after discharge using the Wake Forest Physician Trust Scale (WFPTS), [42] which measures the interpersonal relationship between patient and provider in domains of fidelity, competence, honesty, and overall. Given the nature of the medical teams in an academic hospital, the wording is modified to refer to all inpatient physicians who took care of them, rather than to a specific physician.

The quality of communication with inpatient providers is measured using items from the Interpersonal Processes of Care in Diverse Populations instrument (IPC), $[43,44]$ which assesses clarity of explanations, responsiveness to patient concerns, and involvement of patients in decision-making.

\section{Disease self-management}

Health self-efficacy is assessed using a shortened 2-item version of the Perceived Health Competence Scale 
(PHCS) [45]. Resilient coping, beliefs consistent with the ability to rebound from or positively adapt to significant stressors, is measured by the 4-item Brief Resilient Coping Scale (BRCS) [46]. The presence and severity of depressive symptoms at baseline is measured using the Patient Health Questionnaire (PHQ-8), [47] which is readministered during the 30-day follow up interview, as both prevalent and incident depression are common in this setting and impact multiple outcomes [48]. Other health behaviors, such as tobacco/alcohol use, diet, and exercise are measured using the Centers for Disease Control (CDC) Behavioral Risk Factor Surveillance System (BRFSS), [49] the Starting the Conversation (STC) scale, [50] and the Exercise Vital sign, [51] respectively. Post-discharge stress is assessed as well (Table 1).

Medication adherence before hospitalization and 30 days after discharge is self-reported using a shortened 7item version of the Adherence to Refills and Medicines Scale (ARMS) [52]. Post-discharge medication discrepancies are measured by eliciting a medication history from participants, comparing it to the list of discharge medications in the health record, and probing the reasons for any differences [53]. The RA further assesses participants' understanding by asking them to provide the indication, dose, and frequency for representative cardiac medications [54].

\section{Health outcomes}

General health-related quality of life, as well as functional status for all participants, is assessed using the full PROMIS 10-item measure of global physical and mental health, [27] as well as the EQ-5D [55]. Functional status for participants age 65 or older is re-assessed at 30 and 90 days post-discharge using the VES-13, described above.

Unplanned health care utilization, including emergency department visits and unplanned readmission, is assessed at 30 and 90 days after discharge from the index hospitalization, using a combination of participant report and internal as well as external medical record review.

Mortality data will be gathered for up to 3.5 years after hospital discharge, using a combination of data from the Social Security Administration, [56] medical documentation in the electronic health record, family report, and obituaries.

\section{Statistical analysis}

The primary outcomes of interest are mortality and 30and 90-day unplanned health care utilization. Additional outcomes include post-discharge medication discrepancies, functional status, and quality of life.

Cox proportional hazard regression models will be constructed to examine the impact of health literacy, other patient characteristics, and hospital discharge quality on unplanned health care utilization and mortality [57]. Semi-competing risk models will be used for analyses since mortality, an absorbing state, precludes readmission but not vice versa [58]. The models will include independent variables from eight broad categories that are hypothesized to influence post-discharge outcomes. They include: a) sociodemographic factors; b) health status; c) health literacy/numeracy; d) social support; e) patient-system factors; f) patient-provider factors; g) self-management; and h) care transition quality. Due to the large number of independent variables, data reduction techniques including principal component and redundancy analyses will be conducted to reduce the chance of model overfitting [59]. Smoothed Schoenfeld residuals will be used to graphically test for departure from the proportional hazards assumption [60]. With interest in understanding how health literacy may moderate the quality of discharge and outcomes among different populations, interactions between health literacy and demographic groups (e.g., age, gender, race), illness burden (e.g., Elixhauser index), and levels of social support (e.g., ESSI) will be examined. Likelihood ratio tests will be used for tests of interactions. Due to the large number of variables being collected, missing data are likely to be observed. We will use multiple imputation techniques to validly address bias and uncertainty associated with the missing data. Analyses will be performed in the $\mathrm{R}$ programming language (www.r-project.org).

In addition to the primary analyses, and guided by the conceptual framework depicted in Figure 1, path models will be constructed to explore the relationships among exogenous variables (e.g., age, health literacy, social support) and endogenous mediator (e.g., access to care, selfefficacy/health competence, resilient coping) and outcome variables (e.g., unplanned health care utilization, mortality). Model fit will be quantified with the comparative fit index, [61] the root mean square error of approximation, and the adequacy index [59]. Bootstrap-based resampling will be used to accurately summarize the potential for model overfitting and optimism.

\section{Power and sample size}

We will enroll 3,000 patients, all of whom will be observed for mortality until one year after the last patient is enrolled. Health care utilization and mortality data will be collected electronically and by medical record review, so we anticipate greater than $95 \%$ availability of those data. Over the course of follow-up, which will vary from one year (late enrollees) to 3.5 years (early enrollees), we anticipate the mortality rate to be approximately $23 \%$. This is based on the assumptions that $63 \%$, $32 \%$, and $5 \%$ of the enrolled patients will have ACS, ADHF, and both ACS and ADHF diagnoses, respectively; one-year mortality rates will be approximately $4 \%$, $[5,6]$ $27 \%$, [8] and 14\%, [62] respectively; the time until death 
distribution will be approximately exponential; and the administrative censoring distribution (due to the end of the study) will be approximately uniform from one to 3.5 years.

Using a distribution of previously observed patients at Vanderbilt University Hospital, we anticipate participants to fall into the health literacy strata on the s-TOFHLA as follows: $10 \%$ inadequate, $9-10 \%$ marginal, and $80 \%$ adequate [53]. Assuming s-TOFHLA scores are uniformly distributed in each stratum, we conducted a simulationbased calculation to explore power as a function of sTOFHLA effect size while adhering to the diagnostic composition (ACS, ADHF, and both) of the sample. The power to detect a $7.5 \%, 8.75 \%$, and $10 \%$ drop in the hazard rate for death per 6-point increase on the s-TOFHLA scale was $80 \%, 90 \%$ and $96 \%$, respectively.

\section{Enrollment to date}

Between October 2011 and August 2013, 5350 patients were determined by clinical chart screening to have ADHF and/or intermediate to high likelihood of ACS. Some patients did not complete the full assessment of study eligibility due to logistical reasons such as rapid patient discharge (24.3\%), declining to be screened (17.0\%), or inhospital death before screening was completed (1.4\%). The remaining $57.3 \%$ of patients with ADHF and/or ACS completed the eligibility assessment. Among them, 50.0\% were determined to be eligible, and $81.5 \%$ of eligible patients enrolled in the study. The most common reasons for ineligibility among those who completed screening were previous enrollment in VICS or a conflicting study (14.6\%), or being too ill $(13.8 \%)$ or too cognitively impaired $(6.8 \%)$ to complete the study questionnaires.

As of August 2013, 1249 patients were enrolled. Participants had a median age of 60 at enrollment, 55.0\% were male, and $59.6 \%$ were married or living with someone (Table 2). Most (62.7\%) presented with ACS, while 29.7\% had ADHF, and 7.6\% had both conditions. In this referral center, study participants are a geographically diverse group, residing in 143 counties across 15 states. In educational attainment, $44.7 \%$ reported a high school education or less. On the s-TOFHLA, $11.8 \%$ had inadequate health literacy, and $7.4 \%$ had marginal health literacy.

Completion of follow-up calls thus far demonstrates high levels of patient retention-88.2\% at 2-3 days, $88.0 \%$ at 30 days, and $86.4 \%$ at 90 days after discharge.

\section{Discussion}

The period following hospital discharge is a vulnerable time for patients, as they adjust to new medications, recover from acute illness, and cope with the challenges of acute and chronic diseases. While biomedical research has produced large advances in clinical care and the concept of personalized medicine has introduced
Table 2 Participant characteristics $(\mathrm{N}=1,249)$

\begin{tabular}{|c|c|}
\hline Age, median (IQR) & $60(52-69)$ \\
\hline Male gender & $687(55.0)$ \\
\hline \multicolumn{2}{|l|}{ Diagnosis } \\
\hline ACS & $783(62.7)$ \\
\hline $\mathrm{ADHF}$ & $371(29.7)$ \\
\hline Both & $95(7.6)$ \\
\hline \multicolumn{2}{|l|}{ Race $^{*}$} \\
\hline White & $1029(82.4)$ \\
\hline Black & $192(15.4)$ \\
\hline Other & $25(2.0)$ \\
\hline Hispanic/latino ethnicity & $24(1.9)$ \\
\hline \multicolumn{2}{|l|}{ Marital status } \\
\hline Married/living with partner & $744(59.6)$ \\
\hline Separated/divorced & $228(18.3)$ \\
\hline Widowed & $157(12.6)$ \\
\hline Single/never married & $120(9.6)$ \\
\hline $\begin{array}{l}\text { Number of people who live at home (not including } \\
\text { patient), median (IQR) }\end{array}$ & $1(1-2)$ \\
\hline \multicolumn{2}{|l|}{ Years of education } \\
\hline 0-8 (i.e. no high school) & $50(4.0)$ \\
\hline 9-11 (i.e. some high school) & $127(10.2)$ \\
\hline 12/GED & $381(30.5)$ \\
\hline 13-15 (i.e. some college) & $390(31.2)$ \\
\hline 16 (i.e. college graduate) & $161(12.9)$ \\
\hline $17+$ & $140(11.2)$ \\
\hline \multicolumn{2}{|l|}{ Health literacy* } \\
\hline Inadequate & $148(11.8)$ \\
\hline Marginal & $92(7.4)$ \\
\hline Adequate & $970(77.7)$ \\
\hline
\end{tabular}

Values are given as $\mathrm{N}(\%)$ unless otherwise noted. $\mathrm{IQR}=$ interquartile range. *Missing values: race $(\mathrm{N}=3,0.2 \%)$, health literacy $(\mathrm{N}=39,3.1 \%)$.

customized pharmacology, there is an additional need to better characterize social determinants of health that influence patient outcomes. Most prior work on postdischarge outcomes has utilized administrative datasets or registries that may lack detailed information on social determinants. The Vanderbilt Inpatient Cohort Study will bring several unique contributions to the literature, including robust assessment of health literacy, social support, and other aspects of engagement with the health care system; enrollment of patients from a referral center and affiliated hospital in the South, where the burden of ACS and ADHF is high; and outcomes that include selfmanagement, functional status, quality of life, health care utilization, and mortality. Overall, VICS seeks to identify predictors of health outcomes during this vulnerable time, determine their interrelationships, and suggest which may be suitable for intervention or customized care. 


\section{Abbreviations}

ADLs: Activities of daily living; ACS: Acute coronary syndromes; ADHF: Acute decompensated heart failure; ARMS: Adherence to refills and medicines scale; AMA: Against medical advice; BRFSS: Behavioral risk factor surveillance system; BHLS: Brief health literacy screen; BRCS: Brief resilient coping scale; CTM-3: Care transitions measure-3; CES-D: Center for epidemiologic studies depression scale; CDC: Centers for disease control; eHEALS: eHealth literacy scale; EKG: Electrocardiogram; ESSI: ENRICHD Social Support Inventory; EDW: Enterprise data warehouse; GBAS: Generic brief acculturation scale; HRS: Health and retirement survey; HCSDS: Health care system distrust scale; IADLs: Instrumental activities of daily living; ISD: Instrumental support after discharge; IPC: Interpersonal processes of care in diverse populations instrument; MIDUS: Midlife development in the United States; PHQ: Patient health questionnaire; PROMIS: Patient reported outcomes measurement information system; PHCS: Perceived health competence scale; PSDM: Problem-solving decision-making scale; RA: Research assistant; REDCap: Research electronic data capture; s-TOFHLA: Short form of the test of functional health literacy in adults; SPMSQ: Short portable mental status questionnaire; STC: Starting the conversation; SNS: Subjective numeracy scale; TIMI: Thrombolysis in myocardial infarction; VICS: Vanderbilt inpatient cohort study; VES-13: Vulnerable elders survey; WFPTS: Wake forest physician trust scale.

\section{Competing interests}

Dr. Kripalani is a consultant to and holds equity in PictureRx, LLC, which has no role in the design or performance of this study.

\section{Authors' contributions}

Conception and design (AGM, AS, KAW, CC, EEV, KMG, CMD, RLR, LDC, KMD, JFS, SB, JSS, CYO, FEH, SK); acquisition, analysis, and interpretation of data (CC, KMG, JSS, SK); drafting of manuscript (AGM, AS, KAW, CC, EEV, JSS, SK); critical revision of manuscript (AGM, AS, KAW, CC, EEV, KMG, CMD, RLR, LDC, KMD, JFS, SB, JSS, CYO, FEH, SK). All authors read and approved the final manuscript.

\section{Acknowledgements}

Funded by the National Heart, Lung, and Blood Institute (R01 HL109388, Kripalani) and in part by K23 AG040157 (Vasilevskis) and the National Center for Advancing Translational Sciences (2 UL1 TR000445-06). The research reported/outlined here was supported in part by the Department of Veterans Affairs, Veterans Health Administration, Health Services Research and Development Service. Dr. Salanitro is a VA HSR\&D Career Development awardee at the Nashville VA. The content is solely the responsibility of the authors and does not necessarily represent official views of the National Institutes of Health or the Department of Veterans Affairs. The authors' funding sources did not participate in the planning, collection, analysis or interpretation of data or in the decision to submit for publication.

\section{Author details}

${ }^{1}$ Vanderbilt University School of Medicine, Nashville, TN, USA. ${ }^{2}$ VA Tennessee Valley Geriatric Research Education Clinical Center (GRECC), HSR\&D Targeted Research Enhancement Program for Patient Healthcare Behavior, Nashville, TN, USA. ${ }^{3}$ Clinical Research Center of Excellence (CRCoE), Nashville, TN, USA. ${ }^{4}$ Division of General Internal Medicine and Public Health, Department of Medicine, Vanderbilt University, 1215 21st Ave S, Suite 6000 Medical Center East, Nashville 37232, TN, USA. ${ }^{5}$ School of Nursing, Vanderbilt University, Nashville, TN, USA. ${ }^{6}$ Center for Health Services Research, Vanderbilt University, Nashville, TN, USA. 'Department of Sociology, Vanderbilt University, Nashville, TN, USA. ${ }^{8}$ Center for Quality Aging, Vanderbilt University, Nashville, TN, USA. ${ }^{9}$ Division of Cardiovascular Medicine, Vanderbilt University, Nashville, TN, USA. ${ }^{10}$ Department of Biostatistics, Vanderbilt University, Nashville, TN, USA. ${ }^{11}$ Department of Biomedical Informatics, Vanderbilt University, Nashville, TN, USA.

Received: 27 September 2013 Accepted: 3 January 2014 Published: 8 January 2014

\section{References}

1. Kripalani S, Jackson AT, Schnipper JL, Coleman EA: Promoting effective transitions of care at hospital discharge: a review of key issues for hospitalists. J Hosp Med 2007, 2(5):314-323.
2. Jencks SF, Williams MV, Coleman EA: Rehospitalizations among patients in the Medicare fee-for-service program. N Engl J Med 2009, 360(14):1418-1428.

3. Ho PM, Bryson CL, Rumsfeld JS: Medication adherence: its importance in cardiovascular outcomes. Circulation 2009, 119(23):3028-3035.

4. Curtis JP, Schreiner G, Wang Y, Chen J, Spertus JA, Rumsfeld JS, Brindis RG, Krumholz HM: All-cause readmission and repeat revascularization after percutaneous coronary intervention in a cohort of Medicare patients. J Am Coll Cardiol 2009, 54(10):903-907.

5. Pendyala LK, Torguson R, Loh JP, Kitabata H, Minha S, Badr S, Dvir D, Barbash IM, Satler LF, Pichard AD, et al: Comparison of adverse outcomes after contemporary percutaneous coronary intervention in women versus men with acute coronary syndrome. Am J Cardiol 2013, 111(8):1092-1098.

6. Bakhai A, Ferrieres J, Iniguez A, Sartral M, Belger M, Schmitt C, Zeymer U, APTOR Trial Investigators: Clinical outcomes, resource use, and costs at 1 year in patients with acute coronary syndrome undergoing PCl: results from the multinational APTOR registry. J Intervent Cardio/ 2012, 25(1):19-27.

7. Ross JS, Chen J, Lin Z, Bueno H, Curtis JP, Keenan PS, Normand SL, Schreiner G, Spertus JA, Vidan MT, et al: Recent national trends in readmission rates after heart failure hospitalization. Circ Heart Fail 2010, 3(1):97-103.

8. Alter DA, Ko DT, Tu JV, Stukel TA, Lee DS, Laupacis A, Chong A, Austin PC: The average lifespan of patients discharged from hospital with heart failure. J Gen Intern Med 2012, 27(9):1171-1179.

9. Kansagara D, Englander H, Salanitro A, Kagen D, Theobald C, Freeman M, Kripalani S: Risk prediction models for hospital readmission: a systematic review. JAMA 2011, 306(15):1688-1698.

10. Arnold SV, Chan PS, Jones PG, Decker C, Buchanan DM, Krumholz HM, Ho PM, Spertus JA, Cardiovascular Outcomes Research Consortium: Translational research investigating underlying disparities in acute myocardial infarction patients' health status (TRIUMPH): design and rationale of a prospective multicenter registry. Circ Cardiovasc Qual Outcomes 2011, 4(4):467-476

11. Lichtman JH, Lorenze NP, D'Onofrio G, Spertus JA, Lindau ST, Morgan TM, Herrin J, Bueno H, Mattera JA, Ridker PM, et al: Variation in recovery: role of gender on outcomes of young AMI patients (VIRGO) study design. Circ Cardiovasc Qual Outcomes 2010, 3(6):684-693.

12. Calvillo-King L, Arnold D, Eubank KJ, Lo M, Yunyongying P, Stieglitz H, Halm EA: Impact of social factors on risk of readmission or mortality in pneumonia and heart failure: systematic review. J Gen Intern Med 2013, 28(2):269-282

13. Waring ME, McManus RH, Saczynski JS, Anatchkova MD, McManus DD, Devereaux RS, Goldberg RJ, Allison JJ, Kiefe Cl: TRACE-CORE investigators: transitions, risks, and actions in coronary events-center for outcomes research and education (TRACE-CORE): design and rationale. Circ Cardiovasc Qual Outcomes 2012, 5(5):e44-e50.

14. Institute of Medicine: Unequal Treatment: Confronting Racial and Ethnic Disparities in Health Care. Washington, DC: National Academies Press; 2003.

15. Commission on Social Determinants of Health: Closing the gap in a generation: health equity through action on the social determinants of health. In Final report of the Commission on Social Determinants of Health. Geneva: World Health Organization; 2008.

16. Institute of Medicine: Health literacy: a prescription to end confusion. Washington, DC: National Academies Press; 2004.

17. Mitchell SE, Sadikova E, Jack BW, Paasche-Orlow MK: Health literacy and 30-day postdischarge hospital utilization. J Health Commun 2012, 17(Suppl 3):325-338.

18. Sudore RL, Yaffe K, Satterfield S, Harris TB, Mehta KM, Simonsick EM, Newman AB, Rosano C, Rooks R, Rubin SM, et al: Limited literacy and mortality in the elderly: the health, aging, and body composition study. J Gen Intern Med 2006, 21(8):806-812.

19. Hansen LO, Young RS, Hinami K, Leung A, Williams MV: Interventions to reduce 30-day rehospitalization: a systematic review. Ann Intern Med 2011, 155(8):520-528.

20. Burke RE, Kripalani S, Vasilevskis EE, Schnipper JL: Moving beyond readmission penalties: creating an ideal process to improve transitional care. J Hosp Med 2013, 8(2):102-109.

21. Paasche-Orlow MK, Wolf MS: The causal pathways linking health literacy to health outcomes. Am J Health Behav 2007, 31(Suppl 1):S19-S26.

22. Harris PA, Taylor R, Thielke R, Payne J, Gonzalez N, Conde JG: Research electronic data capture (REDCap)-a metadata-driven methodology and 
workflow process for providing translational research informatics support. J Biomed Inform 2009, 42(2):377-381.

23. Norris AE, Phillips RE, Kang HP: Evaluation of a generic brief acculturation scale in a sample of male enlisted naval personnel. Clin Nurse Spec 2008, 22(4):172-178.

24. Pfeiffer $\mathrm{E}: \mathrm{A}$ short portable mental status questionnaire for the assessment of organic brain deficit in elderly patients. J Am Geriatr SoC 1975, 23(10):433-441.

25. Antman EM, Cohen M, Bernink PJ, McCabe CH, Horacek T, Papuchis G, Mautner B, Corbalan R, Radley D, Braunwald E: The TIMI risk score for unstable angina/non-ST elevation Ml: a method for prognostication and therapeutic decision making. JAMA 2000, 284(7):835-842.

26. Elixhauser A, Steiner C, Harris DR, Coffey RM: Comorbidity measures for use with administrative data. Med Care 1998, 36(1):8-27.

27. Hays RD, Bjorner JB, Revicki DA, Spritzer KL, Cella D: Development of physical and mental health summary scores from the patient-reported outcomes measurement information system (PROMIS) global items. Qual Life Res 2009, 18(7):873-880.

28. Saliba D, Elliott M, Rubenstein LZ, Solomon DH, Young RT, Kamberg CJ, Roth C, MacLean CH, Shekelle PG, Sloss EM, et al: The vulnerable elders survey: a tool for identifying vulnerable older people in the community. J Am Geriatr Soc 2001, 49(12):1691-1699.

29. Radloff LS: The CES-D scale: a self-report depression scale for research in the general population. Applied Psychol Meas 1997, 3:385-401.

30. Nurss JR, Parker RM, Williams MV, Baker DW: Short test of functional health literacy in adults. Snow Camp, NC: Peppercorn Books and Press; 1998.

31. Chew LD, Bradley KA, Boyko EJ: Brief questions to identify patients with inadequate health literacy. Fam Med 2004, 36(8):588-594.

32. Fagerlin A, Zikmund-Fisher BJ, Ubel PA, Jankovic A, Derry HA, Smith DM: Measuring numeracy without a math test: development of the subjective numeracy scale. Med Decis Making 2007, 27(5):672-680.

33. Juster FT, Suzman R: An overview of the health and retirement survey. J Hum Resources 1995, 30(suppl):S7-S56.

34. Rossi AS: Social responsibility to family and community. In How healthy are we? A national study of well-being at midlife. Edited by Brim OG, Ryff CD, Kessler RC. Chicago: University of Chicago Press; 2004:550-585.

35. Mitchell PH, Powell L, Blumenthal J, Norten J, Ironson G, Pitula CR, Froelicher ES, Czajkowski S, Youngblood M, Huber M, et al: A short social support measure for patients recovering from myocardial infarction: the ENRICHD social support inventory. J Cardiopulm Rehabil 2003, 23(6):398-403.

36. Shea JA, Micco E, Dean LT, McMurphy S, Schwartz JS, Armstrong K: Development of a revised health care system distrust scale. J Gen Intern Med 2008, 23(6):727-732.

37. Norman CD, Skinner HA: eHEALS: the eHealth literacy scale. J Med Internet Res 2006, 8(4):e27.

38. Southern WN, Nahvi S, Arnsten JH: Increased risk of mortality and readmission among patients discharged against medical advice. Am Med 2012, 125(6):594-602.

39. Graumlich JF, Novotny NL, Aldag JC: Brief scale measuring patient preparedness for hospital discharge to home: psychometric properties. J Hosp Med 2008, 3(6):446-454.

40. Coleman EA, Mahoney E, Parry C: Assessing the quality of preparation for posthospital care from the patient's perspective: the care transitions measure. Med Care 2005, 43(3):246-255.

41. Ende J, Kazis L, Ash A, Moskowitz MA: Measuring patients' desire for autonomy: decision making and information-seeking preferences among medical patients. J Gen Intern Med 1989, 4(1):23-30.

42. Hall MA, Zheng B, Dugan E, Camacho F, Kidd KE, Mishra A, Balkrishnan R: Measuring patients' trust in their primary care providers. Med Care Res Rev 2002, 59(3):293-318.

43. Kripalani S, Jacobson TA, Mugalla Cl, Cawthon RC, Niesner KJ, Vaccarino V: Health literacy and the quality of physician-patient communication during hospitalization. J Hosp Med 2010, 5(5):269-275.

44. Stewart AL, Napoles-Springer A, Perez-Stable EJ, Posner SF, Bindman AB, Pinderhughes HL, Washington AE: Interpersonal processes of care in diverse populations. Milbank Q 1999, 77:305-339.

45. Smith MS, Wallston KA, Smith CA: The development and validation of the perceived health competence scale. Health Educ Res 1995, 10(1):51-64

46. Sinclair VG, Wallston KA: The development and psychometric evaluation of the brief resilient coping scale. Assessment 2004, 11(1):94-101.
47. Kroenke K, Spitzer RL, Williams JB, Lowe B: The patient health questionnaire somatic, anxiety, and depressive symptom scales: a systematic review. Gen Hosp Psychiatry 2010, 32(4):345-359.

48. Parashar S, Rumsfeld JS, Spertus JA, Reid KJ, Wenger NK, Krumholz HM Amin A, Weintraub WS, Lichtman J, Dawood N, et al: Time course of depression and outcome of myocardial infarction. Arch Intern Med 2006, 166(18):2035-2043.

49. Centers for Disease Control and Prevention: Behavioral risk factor surveillance system. Available at http://www.cdc.gov/brfss/index.htm. Accessed March 10, 2010.

50. Paxton AE, Strycker LA, Toobert DJ, Ammerman AS, Glasgow RE: Starting the conversation performance of a brief dietary assessment and intervention tool for health professionals. Am J Prev Med 2011, 40(1):67-71.

51. Sallis R: Developing healthcare systems to support exercise: exercise as the fifth vital sign. Br J Sports Med 2011, 45:473-474

52. Kripalani S, Risser J, Gatti M, Jacobson TA: Development and evaluation of the adherence to refills and medications scale (ARMS) among lowliteracy patients with chronic disease. Value Health 2009, 12(1):118-123.

53. Kripalani S, Roumie CL, Dalal AK, Cawthon C, Businger A, Eden SK, Shintani A, Sponsler KC, Harris $L$, Theobald C, et al: Effect of a pharmacist intervention on clinically important medication errors after hospital discharge: a randomized controlled trial. Ann Intern Med 2012, 157(1):1-10.

54. Marvanova M, Roumie CL, Eden SK, Cawthon C, Schnipper JL, Kripalani S: Health literacy and medication understanding among hospitalized adults. J Hosp Med 2011, 6:488-493.

55. EuroQol Group: EQ-5D. Available at http://www.eurogol.org/. Accessed June 20, 2013.

56. Social security online: research, statistics, \& policy analysis. Available at: http://www.ssa.gov/policy/about/epidemiology.html. Accessed June 20, 2013.

57. Cox DR: Regression models and life tables (with discussion). J R Stat Soc Series B 1972, 34(2):187-220.

58. Fine JP, Jiang $\mathrm{H}$, Chappell R: On semi-competing risks data. Biometrika 2001, 88(4):907-919.

59. Harrell FE Jr: Regression Modeling Strategies With Applications to Linear Models, Logistic Regression, and Survival Analysis. New York, NY: Springer-Verlag; 2001

60. Schoenfeld D: Partial residuals for the proportional hazards regression model. Biometrika 1982, 69(1):239-241.

61. Bentler PM: Comparative fit indexes in structural models. Psychol Bull 1990, 107(2):238-246.

62. Kaul P, Ezekowitz JA, Armstrong PW, Leung BK, Savu A, Welsh RC, Quan H, Knudtson ML, McAlister FA: Incidence of heart failure and mortality after acute coronary syndromes. Am Heart J 2013, 165(3):379-385. e372.

doi:10.1186/1472-6963-14-10

Cite this article as: Meyers et al:: Determinants of health after hospital discharge: rationale and design of the Vanderbilt Inpatient Cohort Study (VICS). BMC Health Services Research 2014 14:10.

\section{Submit your next manuscript to BioMed Central and take full advantage of:}

- Convenient online submission

- Thorough peer review

- No space constraints or color figure charges

- Immediate publication on acceptance

- Inclusion in PubMed, CAS, Scopus and Google Scholar

- Research which is freely available for redistribution

Submit your manuscript at www.biomedcentral.com/submit
C Biomed Central 